\title{
Technical Change and Social Revolution
}

The concept and the term "industrial revolution" are far from being universally accepted. Historians and economists with a conservative inclination tend to criticize them more or less severely. My general thesis is that the "industrial revolution" has been, in the first place, a true revolution, that is an epoch making break with the past. In the second place, that such a break has not been so far fully analyzed in its impact on the global society. The "industrial revolution" has been undoubtedly explored and discussed especially by the economic historians in its social, economic, and political terms. This is necessary, but not sufficient. The critical examination of its broad culture and scientific impact is lagging behind. In particular, it has not been fully recognized that power and science, as a result of the industrial revolution, have changed their nature. The bases of legitimacy for power have shifted from traditional or democratic acceptance to rational accountability.

Science has become a group enterprise and an organizational weapon capable of deeply influencing the political power structure, the economic system of production, and the overall social and the intellectual climate. In this respect, I submit that the "industrial revolution" has been indeed a genuine revolution, a conception that is essentially alien to the classical political thought. Naturally, no genuine revolution can happen abruptly like Minerva being born fully armored ex capite Jovis.

The most vocal critic of the concept of "industrial revolution" has been perhaps the well known economist Friedrich A. von Hayek, ${ }^{1}$ a recognized member of the Austrian school of economics and author of the famous pamphlet the Road to Serfdom in which a savage attack was mounted against any kind of government planning in the immediate post war years and to which an equal fierce rebuttal was served by the pro-labor political scientist Herman Finer in his book, The Road to Reaction. Leaving aside such interesting polemical exchanges, it is safe to say that Hayek's general theoretical position is best expressed in his The counter-Revolution of Science. The industrial revolution is here seen as a chapter, as it were, of a trend toward a conception of science as the only source not only of human knowledge but also of any moral obligation. In this way, the triumph of the "esprit polytechnicien", as he calls it, covers and comprises in its realm the whole of human experience in such a way as to deny any value, both cognitive and ethical, to attitudes and experiences not susceptible of exact, "scientific" measurement.

This would amount in the end, according to Hayek, to the reduction of science to "scientism" and would lead necessarily to a dogmatic position which would per se

\footnotetext{
${ }^{1}$ See Friedrich A. Von Hayek, editor, Capitalism and the Historians, The University of Chicago Press, Chicago, 1954.
} 
constitute a total denial of a truly human problematic awareness, and therefore of science itself. ${ }^{2}$

Perhaps because of Hayek's powerful caveat, in most writings about the industrial revolution, despite the fact that everybody seems to accept the idea that it was a definite break, a fracture, in the traditional everyday routine of social life, the concept of revolution has been laid down. Rather, the emphasis has been laid on the political and social continuities with the feudal, premodern past. Instead of elaborating on the revolutionary break, the "great transformation", as Carl Polany called it, has been explored and underlined especially on its evolutionary developments. The reaction against the concept and the term of "industrial revolution" has gone so far as to reject them as purely mythical fabrications. Even the most famous historian of this phenomenon, T.S. Ashton, seems to entertain serious doubts about its nature. He finally rejects the term "revolution" because of its political and ideological origin. It is true, in fact that the term and the aura surrounding it were the work of French revolutionists, certainly more prone to arouse public passions than to examine cold-bloodedly historical phenomena. Just like the other famous phrase "Laisses-faire; laisses-passer", according to Ashton "industrial revolution" belongs to the vocabulary of militant politics and has little, if anything, to do with economic scientific analysis.

In Ashton judgment, the concept of "industrial revolution" was therefore a product of revolutionary agitators of the second half of the XVIII century. It was certainly not the result of a proper historical investigation. It was used and spread extensively by French revolutionary orators and not by British economists or industrialists. It is one of those catch phrases that function like doctrinaire beliefs or effective ideological barriers, preventing he scrupulous historian to perform his duty as regards the periods and the phenomena he is devoting his attention to. ${ }^{3}$

From this peculiar point of view, no wonder that Ashton denounces the typical abstract or doctrinaire nature of many theories even though propounded by such classical authors as Marx or Sombart or Schumpeter.

Ashton's critique easily reaches a vitriolic acme, which does not seem acceptable at least as regards the heuristic necessity for the historian to go beyond petty details, if not misplaced concreteness, in order to achieve a meaningful historical synthesis and not finding only the specific "pearls" as it were, of a minute, painstaking philological exercise.

\footnotetext{
${ }^{2}$ It is hardly necessary to say that the most comprehensive criticism of "scientism" of Galiteian ascendancy is to be found in the works of the founder of phenomenology, Edmund Husserl; see my Scienza e coscienza, Bologna, CED, 2014

${ }^{3}$ For a general examination of the position of T. S. Ashton, especially as expounded in his The Industrial Revolution,see my "II rapporto sociale nel' impresa moderna", Arnauds ed., Roma,1961, in particular pp. 15-21.
} 
There can be no doubt that history is, and it must be, a coherent interpretive narrative and not simply a sequence of discrete, although scientifically ascertained, facts. On the other hand, the good historian should refrain from applying a purely formal and to an extent arbitrary dialectical scheme to the single historical phenomena.

If the historian gives in to this external and schematic dialectics not only history loses its human, that is dramatic, because up to a point peculiarly unpredictable character. Its meaning is actually lost. It simply becomes the gradual emerging of the inevitable. A common target of Ashton as well as of Louis M. Hacker, W.H. Hutt, and others is the American historian Charles A. Beard, author of a controversial Economic Interpretation of the American Constitution and of the monumental work, The rise of the American Civilization. Most polemical strictures against Beard could be easily accepted, especially when they are referred to the abstract and somewhat naïve liberalism of Beard, as in the contribution by Hacker.

The shortcomings of American Liberalism that tends to view the evils of the world as depending essentially, if not exclusively, on mass illiteracy and ignorance are evident and hardly need any further comment. However, the question of the turning point in American history and, earlier in the European scene with the advent of the capitalism cannot be lightheartedly dismissed. The general anticapitalistic bias of Charles A. Beard as of many other European and American intellectuals, if not as an expression of nostalgia for the medieval convents, as Ludwing von Mises would have it, can be perhaps be traced to a naturally critical attitude taken by the scholars vis-à-vis l'home d'argent, the captain of industry and the captain of business, omitting to consider here that according to Thorstein Veblen, these two types, far from being convergent, indicate two contradictory social agents, the captain of industry being moved by the rational requirements of industrial production while the captain of business being merely a brasseur d'affoires, a more or less shrewd speculator, constantly trying to get something for nothing.

What seems to escape the participants to the debate about the nature of the "industrial revolution", as they were edited by Friedich A. von Hayek in Capitalism and the Historians is the fact that, far from being confined to an internal dispute among historians, the real issue concerns the essence of capitalism and the broad consequences - not only economic or at most political - of its advent in Europe during the XVIII century.

The question of the transition from the middle ages and the feudal social system to the modern capitalistic system has been often squarely faced but usually in a narrow gauged perspective that was bound to miss the interconnection among its various aspects, in particular as regards the impact of technical innovation and the 
new scientific approach to social issues. A classical example of the discussion about the transition from feudalism to capitalism has been offered by such scholars as Paul Sweezy, Maurice Dobb, H.K. Takahashi, Georkes Lefevre, R. Hilton, Christopher Hill, and others. The occasion was given by the critical review by P. M. Sweezy of the book by M. Dobb, Studies in the Development of capitalism (London, 1946), promptly followed by the rebuttal by Dobb himself, who was later joined by the English historians Rodney Hilton and Christopher Hill, the Japanese economist H. K. Takahashi, the French Georges Lefevre and Albert Soboul, and the Italian Giuliano Procacci.

The real beginning of the debate however has to be traced to a thesis put forward by Henri Pirenne in his Histoire économique et sociale du Moyen Age - a thesis shared somewhat uncritically by Paul Sweezy and used by the American liberal economist against the basic Dobb's contentions. According to Pirenne, the most important factor making for the transformations of the rural classes during the XII and XIII centuries is not only the extraordinary population increment. It is rather to be seen in the newly developing cities and in the flourishing of commercial transactions. It seems reasonable, than to expect that the feudal organization, that was quite fit for an epoch in which lack of outlets made it compulsory to rely exclusively on internal consumption, would come to an end when permanent urban markets were established. From this point of view, the fact that feudal organization appears to fall into a state of decay as trade develops, is both for Pirenne and Sweezy highly significant. Dobb maintains, on the contrary, that the reasons for the crisis and final transformation of the feudal economy were mainly internal to feudalism. In this respect, Dobb follows Marx's explanation of the crisis of the feudal system as a clear historical evidence of the structural contradiction between the existing type of social relations and the development of new productive forces, claiming a different relation between masters and workers.

It seems evident that Dobb tries to diminish, if not to eliminate altogether, the importance of the market as a prime mover as far as the decline of feudalism is concerned. He does not accept nor does he agree that the production for the market implies of necessity a kind of production based on a salaried workforce. He rather emphasizes a lack of efficiency intrinsic to the feudal production system - a lack of efficiency made even worse by the growing demands of the ruling social groups. In Dobb's view, there is no possibility of a positive relationship between the closed economy of the feudal system and the external world of the market economy. It seems that Dobb has not properly understood the essential difference between the feudal system and the open market economy, which consists in the fact that the former produces exclusively for the internal consumption whereas the capitalistic system produces for the exchange on the open market.

It is crucial in this connection a passage in Das Kapital (book I, chapter VIII) in which it is forcefully stated that, whenever in a social formation not an exchange value but 
a consumption value is predominant, then inevitably the plus value appears to be limited by a series of more or less broad needs while no limitless need of labor plus emerges from the very nature of the production process.

It is difficult to exaggerate the importance of the Marxian position for the various schools of economic thought. However, it is surprising that such position has been mostly accepted or rejected on philosophical, institutional and historical ground while the technical aspect and the underlining scientific issues have been generally blurred, if not completely overlooked.

Why?

The answer must be looked for in Marx himself. He suffers from an intrinsic contradiction, which he was never able to see, even less to solve. For Marx, as I have elsewhere observed, the basic connotation by which a society may be defined is not, it seems, its technology but its "social structure" or, to put it more precisely, its "class structure". Although changed at times depending on whether we look for it in his systematic works or in his occasional, polemical contribution, such as La misère de la philosophie, a sharp rebuttal to Proudhon's La philosophia de la misère, and The social war in France, the concept of "class" and "class structure" is for Marx the fundamental concept. Were the technological factors to play a determining and really crucial role in historical development, the first relevant consequence would necessarily amount to the dropping of the dialectical approach, since technological development cannot be analyzed or, more simply, does not permit that approach. Its character is cumulative and evolutionary, not dialectical. Its analysis rests on sociological and experimental research, and eludes a dialectical historical approach. The most intellectual daring attempt to unravel the Marxian contradiction in this respect has been made by Costas Axelos who tries to interpret Marx as a "thinker of techniques" without fully realizing the contradiction between techniques and dialectics. ${ }^{4}$

In fact, Axelos' intent is clearly stated as aiming at an analyses of Marxian thought as "a descriptive and dialectical interpretation" of techniques as a human voluntary initiative: "men were naturally prone to division of labor; in the future they will be in a position to devote themselves voluntarily to social activities, going beyond the suffocating framework of the division of labor... One should never lose sight of the very strict connection which binds division of labor to property end the different forms of division of labor to the different forms of property". This attempt has merits. It is true that it seems to overlook the internal contradiction of the Marxian theory. But in a cultural situation in which Marx has been commented upon sub specie philosophica 
it underlines the peculiar nature of Marxian analysis which is not deduced from Platonic ideas nor neo- Kantian categories but is rather outlined and set forth in its day today unfolding through practice and the instruments of practice: "neither politic nor religion, nor art, nor philosophy are for him (Marx) constitutive forces of man's history (even alienated) of the ways in which man and the world are bound together. Practice alone is the source of truth and reality; it is practice that binds man to the world".

This is very well and convincingly put: practice with its instrument that is technology. More than a comment in Marx it sounds like an inspired repetition which fails, however, to see the intrinsic contradiction of Marxian thought between techniques and dialectics. We read, in fact, in the first Book of Das Kapital: "technology discloses men's mode of dealing with Nature, the process of production by which he sustains his life, and thereby also lays bare the mode of formation of his social relations, and the mental conceptions that flow from them. Even every history of religion that fails to take a count of this material bases is uncritical. It is in reality much easier to discover by analysis the earthly core of the misty creations of religion then, conversely, it is to develop from the actual relations of life the corresponding celestialised forms of those relations."

The later method is the only materialistic and therefore the only scientific one. The weak points in the abstract materialism of natural science, a materialism that excludes history and its process, are at once evident from the abstract and ideological conceptions of its spokes men whenever they venture beyond the bounds of their own speciality.

This passage is enlightening. It shows that Marx does not allow any uncritical confrontation between Unterbau and Überbau, that is he does not conceive of any mechanistic production of ideological or moral or philosophical system by the materialistic structure as if this structure were a kind of deus ex machine. Far from opposing mechanistically structure and over structure, Marx insists that one should take a hard look at the practical basis of human existence. No doubt there is in him a large portion of "dialectical impatience" of Hegelian origin but, whenever Marx devotes his attention to specific historical phenomena, (from the Civil war in France to the situation of the working class in England), his critical realism is impressive. In the first Book of Das Capital, especially in the chapters dealing with the working day and with the mechanization of industry, his description of factory life is excellent and should be considered essential to any scientific sociology of work. For instance, with one sentence Marx disposes of the hard-dying legend of the steam engine as the mother of the "industrial revolution", and certainly he does not consider a substitution for it the "clock", as Lewis Mumford would have it. Marx sees with astonishing perceptiveness that the revolutionary machine is actually the machine tool. This is the machine that made the revolution in the form of steam engines necessary. As soon as man, instead 
of working himself with an implement on the matter of his labor, becomes merely the motive power of tool machine, it is a pure accident that "motive power takes the disguise of human muscle: it may equally well take the form of wind, water or steam".

Naturally, as everybody knows, Marx had to pay a rather heavy tribute to Hegelian dialectics. Nevertheless, his approach to substantive historically determined issues is still valid for us today. However, not in the sense that Axelos and other contemporary commentators seem to believe. Marx is an excellent sociologist as far as he is able to connect empirical details to an overall meaning. Unfortunately, at times he does not seem to be able to check the dialectical anticipation thanks to which the transcendence of the empirical level leads to a spurious, that is empty, globality. I submit, however, that in Marx it is logically possible to find a concept of "practice", or praxis, which is not necessarily a metaphysical construction but purely and simply a historical phenomenon. In other words, practice is not an absolute point of departure, a pre-categorial postulate. It is, on the contrary, the specific life-situation. It is not, as in the Heidegger of "The question of techniques", technology in general sub specie aeternitatis. It is the actual "factory system". More than that, although this is only implicit in most thinkers dealing with technology as a global social phenomenon, the factory system is seen as a real system, that is as a complex of rules and regulations which means, essentially, that technology is both a practice and at the same time a power structure. Hence, it is possible to understand that, while the "industrial revolution" might not be a revolution in the proper sense after all, it points to a break with the traditional routine and it forces a new allocation of power among the different social agents. Naturally, industrialization as a global social process involves states of mind as well as organizational, structural aspects of society. It would be idle to speculate on the relative priority of one set of aspects versus the other one - for instance, psychological aspects versus the objective ones- it seems clear, however, that structural problems cannot be reduced to a personal headache.

A more recent debate on the "industrial revolution" and its impact has taken place after the polemical exchange between Maurice Dobb and Paul Sweezy. This debate was stirred by an interesting article by Robert Brenner, which appeared in 1976 in the review Past and Present. The main lines of Brenner's argument are simple enough: if agricultural productivity is important for the transition to capitalism, then why did this transition first occurred in England? The answer by Brenner is still basically a Marxist one. In fact, it is his contention that in England the tendency was toward the formation of larger and larger farming units, the consolidation and the leasing of them to large tenant farmers who would hire rural wage laborers. According to Brenner, the emergence of this peculiarly English structure of class relations made possible the great increase in English agricultural productive and this, in turn, sparked 
the overall economic development. The Brenner debate is still going on. Some scholars in particular argue that Brenner gave too much importance to agricultural productivity difference between England and France; others contend that rather than class factors the technological factors had to be isolated and regarded as the decisive ones while some commentators still insist that agriculture productivity could not be considered as a special and exclusive quality of large-scale capitalist farmers. All these views have some merit but the fact remain that the Brener argument, valid as it is for Europe had actually no effect as an explanation of the rise of capitalism among the English colonies on the eastern side of the Atlantic. In fact, while no large-scale capitalist could be found in an eighteenth century America, it is undeniable that capitalism developed precisely in those regions, like New England in which small-scale family farming was the dominant form of economic activity.

Apparently, culture traits as well as psychological and religious motivations together with structural features of the economic scene must be taken into consideration. In this respect, Weber and Sombart contributions still have some value. Their shortcomings, strangely enough, are shared by the most recent explanation. They have to do with a typical misunderstand of the nature and the role of techniques in economic and social development. We take the term techniques in its large meanings to include invention and their large-scale application, and as such we can use it as a synonym for technology. Technical progress has been so far largely misunderstood. When, confronting the problem of the machine, Heidegger asks: "what is the essence of a modern machine?", the answer he offers is far from satisfactory. He maintains that machine and in general technology cannot be anything else but a new form of the eternal return of the identical.

I have already remarked somewhere else that, expressed in these terms, the problem posed by technology cannot escape a decadent outcome, that is to say one that would confuse important analytic observations with purely suggestive propositions. Needless to say, such propositions, oracular and suggestive as they are, can not be either verified or falsified and of necessity lead to the elaboration of the myth of techniques- a myth which stems from an equivocal experience because it expresses an evaluation of techniques as if techniques were completely alien to us instead of being, as they are, man-made and historically determined, not to mention the fact that anti-machinism is usually a product and attitude of people who have no familiarity with machines and entertain an irrational fear about something they simply ignore.

Marx, as we have seen above, offers some clear and factual description of technical processes and seems now and then to realize the revolutionary impact of the machine technology, but he fails to clarify his intuition about man's work when he states that such work essentially consists in some sort of "metabolic process" which involves man and nature. The basic Marxian tenet seems to be that man exploits nature but at 
the same time such exploitation of nature takes place and is made possible by the fact that man exploits man in exploiting nature- in other words, the exploitation of nature is made possible through the exploitation of man by man; it is, as it were, a second degree exploitation. What Marx misses has to do with the very nature of technology. For him, technology, more than a perfection without purpose, as it has been eloquently argued, has a purely instrumental nature. What both Marx and Marxists fail to see is that technology is not only a mediating tool in the production process. Actually, technology in the present day factory system has become a direct productive force, and science, on the other hand, from which technology derives in the form of applied scientific knowledge, is directly fulfilling a social role and affects both the nature and the allocation of power and resources. Science and knowledge are fast becoming decisive social factors. What one is in a position to control at the present time is what one knows.

Strange as it may seem, perhaps the only major thinker of the XIX century that actually managed to conceive and elaborate the social role of science is the official founder of sociology, Auguste Comte. Far from being a lonely and mysterious enterprise as still has it the popular imagination, science in Comte's view fulfills a basic social role and is a determining force in a modern society. Again, such role is not a merely instrumental one. It has to do with the legitimation basis of modern industrial society as far as this legitimation cannot be referred to tradition nor to metaphysical nor to theological values but is necessarily based on scientific knowledge.

What defines modernity is precisely the new concept of science-no longer a solitary initiative nor an esoteric mysterious knowledge for the happy few, but the social foundation of any society that is daring enough to embark upon a process of renewal cutting off its century old values and beliefs. For Comte, science is not only knowledge, to be conceived as the product of "idle curiosity", to use the famous phrase of Thorstein Veblen; it is knowledge in terms of social process, planning and initiative. How is this possible? The main lines of Comte's reasoning are simple enough. His teacher, SaintSimon, had stated that "mankind is not fit to live in ruins; it needs certainly and stability". After the French Revolution, mankind - I'humanite - had to rebuild its habitats; society needed a total reconstruction. New values had to be discovered and formulated to function as the basic presuppositions for the various social groups. Whence these values could come from? Tradition was over. Old-fashioned theology and speculative philosophy had little, if anything, to offer. Individual wills, on the other hand, were too unpredictable and drastically differentiated to provide a common basis for the new community. Social consensus had to be founded on a totally new basis. Here Comte's contribution emerges as a stroke of genius. Individual will be anarchistic in nature and therefore not to be trusted. But science, on the contrary, has an inter-subjective 
binding value. Science does not depend on individual principles of preference. Science is a public procedure. It is convincing with the pure force of reason. It can act as the new basis for social consensus.

With science as the basis for social cohesion and the binding force of the new community, the historical process which had begun with the early phases of "industrial revolution" seems to have reached its logical outcome. It has been aptly observed that historians used to call it the Industrial Revolution; some social scientists label it modernization; the economic anthropologists Karl Polanyi termed it the "Great Transformation"; Marxists called it the transition from feudalism to capitalism. But by whatever name, it had been known, scholars of all sorts have been fascinated with emergence in the last eighteenth century of the great industrial or capitalistic market economies of the Western world. Now with the collapse of communism in the Soviet Union and Eastern Europe this fascination has taken a new relevance. In its struggle to invent capitalism and market societies in the present, does Eastern Europe have anything to learn from the way it originally happened in the West? The answer is not a comforting one. Great historical experiences cannot be easily exported at will. However, a profound, critical assessment of what happened in the West can perhaps be useful today to the new emerging countries and developing economies all over the world.

What has to be understood and what seems to have escaped so far most commentators and analysts, is the new social function of science and of technology as applied scientific knowledge. We still talk and think having resort to eighteenth century philosophical, economic and political categories, from capitalism to socialism, and do not seem to realize that the new social realities can no longer be accommodated within these categories. The ideological conceptual framework of the eighteenth century is obsolete. It must be realized that science, scientific knowledge and technology as applied science are the new faces of social and political power. It is not enough to talk in terms of information. The concept of information society is at most a stepping stone in the right direction, but it leaves the question of a full understanding of the new society open. Naturally, information plays an important role. But, an important question needs to be asked: what kind of information? Information per se is an elusive and points to a blurred reality. It must be conceived and elaborated as scientific information - that is verified, controllable information.

The role of information in present day developing societies is crucial. Information has become the essential precondition of human development. During the eighteenth and nineteenth centuries, exploitation of man by man was direct and more or less precisely quantifiable. It had to do with the supply of muscular energy, working hours, wages level, and factory discipline. The scenario today is vastly different. The description of the Book I of Das Kapital is no longer tenable. The new 
variables are isolation, segregation, solitude, neglect, exclusion. To be exploited in the modern world means to be on the fringes, to be cut off. Our everyday experiences and common sense might seem to contradict this statement. Mass media continue to spread all over the world. Decisions, at all levels of organized associations, are more numerous, more clamorous, more widely known. However, access to a center where these decisions are taken is more difficult. The center is remote. Its arbitrary nature is consecrated by mystery. It is even hard to determine where exactly this center is located and who forms part. The message of power risks to be the "message of the emperor". Let us set aside the philosophical and sociological theories by which the various power elites defend themselves. Then a curious, and in many ways unexpected, fact must be pointed out. Power today exploits and oppresses not by the use of direct action, which can be objectively and logically assessed on the basis of the aims in view and the results effectively obtained, but simply by ignoring, by failing to intervene, by refusing to take action, by taking refuge behind complex but procedures through which legal formalism and political paralysis come to each other's aid. The most serious sins of power today are sins of omission. The genuine reactionary today is not the man who has a gallows erected or applauds the censor, but the man who prevents action, who preaches resignation at all costs and urges men to put their trust in a spontaneous and practically a automatic evolution.

In this connection, social information has at least three basic functions:

a) it prevents popular initiative from dying away as the result of bureaucratic complications and static self enclosed institutions;

b) it guaranties, up to a point, the effectiveness of the pressure from below as a major democratic instrument capable to ensure people's participation in the process of social transformation;

c) it tends to maintain a degree of contact between political decisions and the aspirations of the citizens, protecting them against both authoritarian rashness and paternalistic tendencies.

These three functions can be fulfilled not by a generally social information but by a type of information based on scientific analysis. It is here that we can fully understand the new role of science as a socially meaningful enterprise as well as the great contribution of August Comte and his motto: "Savoir pour prévoir; prévoir pour agir". Science, and techniques as applied science, that is technology as the general description of the variously interconnected scientific domains and techniques, are essential for the perception and interpretation of present day society. This society cannot be merely described as an information society. One needs to be more precise. It is a society based on scientific information, that is an information that is inter-subjectively binding. A society today can be capitalistic or socialistic or cooperativistic or based on a mixed economy from an ideological and institutional point of view. However, the underlying 
fundamental criterion for its definition goes beyond these external features. It points essentially to the way and to the degree in which science and technology, conceived as applied science, tend to shape its structure and its basic developmental orientation. In this perspective, the importance of science as such, of science in its broadest meaning to include natural and social, or moral, sciences, becomes clear and the famous polemics about the "two cultures" loses much of its value.

The pamphlet by C.P. Snow is well known ${ }^{5}$. My feeling is that it has been grossly overrated. To understand the full impact of modern science one should perhaps take into account the concept and practice of science in classical antiquity. After the successful defense of his hometown, Syracuse, Archimedes would burn his notebooks with the practical lessons from his experiments. The classical scientist did not have much appreciation for practical, useful application. Slaves were available in great numbers. One did not have to have resort to machines as labor saving devices. Moreover, among scholars the fear of menial contamination was widespread and had an arresting effect. It has been properly remarked that Greek science did not arrive at a great technological development because it did not want to reach one. In classical antiquity and during the middle ages, the scientist keeps quiet and by keeping quiet science make the state, the political and religious powers, afraid. It wins respect, if not money. Occasionally, the scientist is persecuted, tortured or killed, but in general he is able to preserve his freedom. It is a fact that the men of power can live, fight, and actually be powerful only as far as the means offered by scientific culture are available. Even the tribal chief depends on the witch- doctor.

As soon as science becomes something different and more than pure speculation and the man of science cannot be seen any longer as a secluded, solitary private Gelehrter, or doctus privatus, and he seems ready to offer his knowledge for social use. Especially in the growing field of industrial production, the situation changes. Already Leonardo is willing to work for the princes and for the king of Frances with his war machines. The scientist is no longer independent. He has traded his autonomy for a position close to power and for the material means to conduct his research. He is no longer a loner; he works more and more in a group, is part of an organization. The processes of "deification", as it were, of science, already traceable to the early Middle Ages, does not correspond to any special illumination of individual scholars shut up in their cells. It rather responds to a compelling question of the society that is being transformed. The correlated crisis in the fall of traditional criteria of judgment, the horizons opened by the contact and paths of communication with other unknown continents, the lessening of the basic legitimacy of the powers which had made themselves exclusive in social terms, had at first reduced and then undermined the ancient legitimating presuppositions of important political and social decisions. The authority of the "eternal

${ }^{5}$ C.P. Snow, The two Cultures and the Scientific Revolution, London and New York, 1960 
yesterday" had been called into question. Once tradition as source of legitimacy had fallen, to whom could one turn? Where could one identify a new instrument of selflistening and self-direction for societies that were as adventurous or imprudent as to enter unto the paths of modernization on a vast scale? Where to find a new basis of social consensus?

Science was the almost obvious answer. It was said that the cultivation of science was an act of homage to God, insofar as it permitted the study of nature, God's own creation. Newton considered God as the supreme Architect, the "pantocrator" and guarantor of the cosmic order. However, modern science seems to possess a unique hybris, a thrust whereby it does not limit itself to reflect nature. It proposes to imitate nature but, at the same time, it invades it, it exploits nature and reinvents it to the point of violating it. Thus, the humility of the scientist as regards nature is an apparent one- it is a tactical move to disarm the adversary and take him by surprise. Bacon had said: "Nature nonnisi parendo vincitur". But Bacon's "obedience to nature" was only the humility that precedes and prepare the triumph, over and against it.

The "sanctification" of science found an unexpected reinforcement in the Puritan ethic that was based on utilitarianism and on the idea that all knowledge should be evaluated, contrary to the wisdom of the classic, on the basis of its utility. In fact, it was thought that everything which helps to make the life of man happier and less hard is good in the eyes of God. Naturally- and on this point utilitarian and Victorian moralities were logical to the point of cruelty- this is to be understood as applying only for all those who deserve it or who pay for their welfare and their "good standing in the community" through methodical daily labor, diligence in undertaking their professional duties, and total dedication to their task. Thus, the completely social life, both individually and collectively, is permeated by scientific spirit and rational calculation. Instrumental reason, as Max Horkheimer would call it, is at present having the upper hand in the already developed societies and in the newly developing countries. It could be said that Auguste Comte is finally enjoying some sort of posthumous revenge. Science and scientists were supposed to serve the existing power. And in fact, they do serve. But in so doing, they condition rather heavily power-holders. The very source of power and the ways in which power is being exercised are more and more deeply affected by science and technology. Even the traditional property rights- such as the private property of invested capital - are undermined by science to the point of fast becoming obsolete as power prerogatives. In large enterprises, there is a clear divorce at present between the power stemming from legal property rights and the power from effective everyday control of operations. Moreover, capitalism can no longer be defined simply by taking into account its rational bookkeeping methods, as Max Weber maintained. Capitalism can be defined even less in Werner Sombart's terms as a "predatory enterprise". 
Present day entrepreneurs have little in common with the demiurgic, romantic innovator at all costs whom Joseph A. Schumpeter used to celebrate a few decades ago. In his slim but rich in thoughts and intuitions book, A theory of economic Development, Schumpeter seems closer to Nietzsche and Max Weber than to Adam Smith or David Ricardo. In the first place, he sees in the entrepreneur a dream coupled with the strong determination to found a private kingdom. In the second place, Schumpeter elaborates on the idea of conquest; in his opinion, there must be in the entrepreneur the impulse to fight, to beat his competitors and to show to everybody that he is the best in his field; finally, just like a poet or an artist, the true entrepreneur must be sensitive to the "joy of creation". In this perspective, the entrepreneur cannot wait for a quick, automatic development of this situation. Contrary to what the classics of economics used to think, he cannot expect the market to force him to develop, to take a dynamic stand expect the market to force him to develop. He must create himself the market. He must anticipate developments, needs and values, which are not yet there. In this sense, far from just begin a good administrator; the true businessperson in Schumpeter's opinion is a charismatic leader, an inventor more than a routine organizer. This romantic portrait has not much to do with the business activity as it is begin conducted at present. Innovation is more than ever necessary. However, innovation is no longer irrational gift of the gods nor the product of the personal charisma. It cannot be divorced from scientific planning. It is a function of rational calculation. It rests on empirically tested knowledge. Moreover, only exceptionally it can be found and organized by a single extraordinary individual. Innovation as well as scientific research have largely become a group activity; they need continuity, multidisciplinary approach, and constant cash flow in an integrated financial plan, implementation and evaluation of specific results.

In this sense, the "industrial revolution", and capitalism stemming from it, determine the emergence of a new society. This society is new not only because it provides new products and new ways of live. It is new because it is based on a new concept of power and because it is endowed with a science rejecting traditional values and transcendent religious dogmas as a basis for moral obligation.

Present day technically advanced societies are therefore essentially characterized by an all-pervading power of scientific knowledge. From a historical point of view, this is a new phenomenon. Its consequences on society as a whole and on science itself are interesting but not easily detectable nor fully understandable. Once science has become a fully organized group activity, it tends almost inevitably towards bureaucratization with an obvious stultifying effect on individual inventiveness. Everybody knows that any scientific research has at least two phases: first, a "context of discovery", in which the research of the research group relies essentially on his or 
its "poetical imagination", as it were; then, in a second phase, there is a predominant development of the "context of validation", in which both the general orienting hypotheses and the specific working hypothesis are duly tested on an empirical basis. Taking this peculiar structure of scientific research into serious consideration, it is impossible or simply a matter of idle speculation to write and talk about "the two cultures and the scientific revolution".

The two cultures, especially as expounded by C.P. Snow, should be the humanistic one and scientific one. The same division among sciences has been often expressed in terms off "soft sciences", that is the sciences of approximation, ${ }^{6}$ and the "hard sciences", that is the exact ones, supposedly capable of exact knowledge as they have a narrow gauged conception of the act of knowing that equates it with quantitative measurement. It does not seem necessary to develop here an analysis as profound as the case would require by calling attention to the critical strictures moved by Edmund Husserl against the "universal geometrical approach" first elaborated by Galileo. What is most necessary is to dispel the purely formal opposition between the "exact" or natural sciences and the sciences dealing with historical, moral and in general humanistic issues. The question whether it is more important to know the second law of thermodynamics or to be well versed with Shakespeare's tragedies is an idle one. What seems to be essential is the ability to pass a global well-reasoned assessment on any pertinent issue at hand. From this point of view, the idyllic apology of the scientist stricto sensu expressed by C.P. Snow in his pamphlet can be in keeping with "conventional wisdom" and even moving at times, given rights to rhetorical quality. But the idea that only the natural scientist is really internationally minded, "democratic", devoid of any petty national loyalty historically grounded, is purely ideological in the sense that it expresses not a truly scientific proposition intersubjectively binding, but a profession of faith, that is a personal principle of preference.

As I have remarked somewhere else, one can state the essence of this pro-"tough science" ideology with a few comments. The scientist is rational because he believes, as the ultimate test of truth, in the cause-effect nexus. He does not need - as Thorstein Veblen would observe with his characteristic ambivalence- a "natural law" or any otherworldly design in order to "gratify his sense of substance". In other words, he does not need a mythical, animistic or anthropomorphic - in any case pre - if not irrational and indemonstrable- network which might justify in his eyes the flux of experience and the chance series of events.

The scientist is thus, supposedly, free as regards emotional prejudices and the cultural idiosyncrasies linked to specific historical contexts. He is "open", by definition, to the new and the different. He has an experimental attitude, a flexible one, which favors

${ }^{6}$ See in this connection Alexandre Koyre, Les philosophers et la machine- Du monde du "à peu-près" à l'univers de la précision. Paris, A. Colin, 1961. 
interpersonal agreement and promotes understanding. One might say, according to C.P. Snow, that he is "naturally" democratic and "socially minded", not infected by any political or culture chauvinism; he is moreover optimistic in temperament, ready to recognize the merits of his colleagues, and so forth.

If one would remember the Lyssenko case under Stalin's rule, not to mention the role of scientists under the Nazi regime, the thesis would soon appear to be intellectual content-free. However, Snow's carries his argument even further. He contrasts the missionary of the past in the technically backward countries with those whom he regards as today's missionaries, the technicians and the scientist.

According to C.P. Snow, many Europeans, from Saint Francis Xavier to dr. Schweitzer, dedicated their lives to the Asians and Africans, nobly but paternally. These are not the Europeans that the Asians and the Africans will welcome with joy under present conditions. They want men who will mix with them as colleagues, who will offer what they know, perform a clear technical task, and will then go away. By good luck, we are dealing here with an attitude, which is easy for scientists. In Snow's view, they are in fact freer than most people of racist sentiments. In their internal climate, the breeze of equality hits you in the face; at times without regard, as it does in Norway. The Norwegian breeze aside, the great Marxist philosopher and activist Antonio Gramsci says nothing different, to technical education in the specialist sense attributes a primacy still more decisive "in the modern world, technical education strictly linked to even the most primitive and unqualified industrial labor, ought to form the basis of the new type of intellectual". With greater caution, Veblen speaks in all his books of the "discipline of the machine" and of the sense of circumscribed and empirically verifiable "factuality" which seemed to constitute the attitude of the engineer or the organizer of production, never to be confused with the typical parasite, the business manager or brasseur d'affaires, interested not in the increase in production through the best combination of production factors, but rather in making money off people's backs by profiting from the cycles of the economic situation. In truth, no one, engineers and writers included, has the future up his sleeve. It is certain that the future does not depend on simple scientific development. Probably it depends on the capacity of critical global evaluation-that is on an integrated humanistic and scientific culture in which science may rediscover its function as regards the meaning of man without pretending to do exhaust such meaning.

The scientific claim is clearly inadmissible. In fact, it reduces all knowledge to a single, scientific knowledge, seen as a "stipulated" knowledge based on methodological rules accepted as valid by a given scientific community. At the same time, it forces one to accept that to know means to measure and that moreover what is not exactly measurable or quantifiable is not knowable. Hence the in temporality of science. For the technocratic ideology and for scientism to which it relates as to its base, science 
properly has no history. It presents itself as the final, necessary and necessitating result of successive discoveries which give rise to the accumulation of the partial results, gradually achieved on the basis of the principle of self-correct ability

There is no doubt that self-correct-ability of specific scientific explanations when faced with new data obtained by research is the essential characteristic of the scientific argument and its process. However, scientific explanation does not live in a historical void nor in social isolation. One cannot ignore the fact, without falling into a disembodied and unreal notion of science, that there are also schools, teachers, loyalties, and betrayals by disciples-a whole, various, multiple world of economic and political interests which influence science and condition the directions of re search. The evolution of science and scientific thought is not reducible to a series of stages simply tied to new discoveries and their internal logic, to "turn-about", to new "paradigms", to use the term of Thomas Kuhn, which is not without ambiguity. The progress of science is not so smooth and "logical" as the scientists would like to have it believed. There is also a story of extra scientific interests, of struggle, of plots, of power, and of blood.

The evolution of science and of its critical self-awareness passes through three basic phases, which I shall allow myself briefly to indicate:

a) the phase of ingenuous idealization of science as dispenser of "divine" knowledge and the source of "laws", uncritically seen as propositions with universal validity, necessary and necessitating;

b) the phase of science as a problematic undertaking, no longer the source of an absolute knowledge, but able at most to arrive at the formulation of trend uniformities and generalizations endowed with a probabilistic validity;

c) the phase in which the scientific explanation tends to be presented as a purely conditional explanation, endowed with a character which is basically operational, in which research, rather than fitting itself to reality or reflecting real processes, tends to present itself as an active, controlled intervention into reality.

It is above all in this last phase that the cult of quantitative decision, and the "quantophrenia": which follows from this, reveal fairly crudely their limits and in particular demonstrate those neo-dogmatic aspects which run the risk of making science itself, as a whole, useless, by denying its basic preconditions. The usefulness which critical reflection on the sacred brings to the discussion of science is in this sense decisive. Outside and beyond any dogmatic temptation, it insists on the return to science as the ability of man to place himself in a problematic relation with himself, with other men, and with the universe.

The arrogance of the quantomaniacs does not recognize the virtue of equilibrium. They call themselves "tough-minded" as against the sentimentalism of those who hold 
to values and do not believe it is possible to restrict the context of human knowledge to the point where it coincides with simple quantitative measurement. Whoever dares to leave the measure of the purely quantitative criterion is stamped as softminded. In reality, even with a dispassionate examination of the question, it seems difficult to resist the temptation of applying to the quantomaniacs the definition of the idiot savant qui sait tout mais qui ne comprend rien. From Quételet to the present, the attempt to apply mathematical reasoning and instruments to the study of social phenomena is an attempt which deserves respect: "at a certain point, towards the end of the nineteenth century" writes Viennese ex-socialist Paul Lazarsfeld, "quantification takes on its modern function in the field of sociology-that of translating ideas into empirical operations and seeking among the variables thus created some recurrent relationships. A whole series of historical studies on specific techniques will be necessary to clarify this general tendency".

This is perfectly understandable and acceptable. What one cannot accept is the narrowing of the meaning of methodology to the point of eliminating from it concepts to make room for the specific techniques. Still worse: the mathematic-statistical instrument is stood on its head as regards its functions, and from an instrument takes on the role of central support.

The idea for two cultures in contrast- humanistic and scientific- does not lead anywhere. Actually, it ends up by denying the very concept of culture as a human problematic awareness that includes both the natural and the mental spheres of experience. However, that contrast is reflected rather unexpectedly on another level. Usually one hears people talking and even writing about the supposed tension between basic, or pure, science and applied science. Nevertheless, the issue is neither so linear nor so simple. No clear-cut separation between pure science and applied science is logically possible or experimentally advisable. In terms of actual research work, the two kinds of science are closely interrelated or, more precisely, interwoven. Fundamental theoretical tools and conceptual framework have often been found and raised during practical, experimental work whereas neither true scientific experiment nor fieldwork can be conducted without an explicit preliminary theoretical guidance. The main reason for such simplistic dichotomy between pure and applied science is not to be found in any intrinsic logic of scientific research. It comes from the outside. It has to do with the usual haste coupled with a typical unawareness of the financial sponsors of scientific ventures. I am not referring only to the fragmentary requests for hard scientific data and forecast coming from the extreme variety of private interests in industry and business. I have in mind the vast and powerful bureaucracies of political parties, pressure groups, labor unions, and so on. Research is called upon to supply data that would give policy makers a good chance to cloak with a scientific jargon 
decisions that usually have already been taken before the scientific data are available. This amounts usually to an exercise in petty rationalization. Science is then being used as a polemical weapon vis-à-vis rivals and competitors.

It is different story when science works for the government or for an international agency, sponsored by various governments. A strange paradox seems then to take place. Science is undoubtedly a tool for government and, at the same time, government and its power are somehow coerced into its service. Between science and power a curious master- servant relationship develops. One has to go back to Hegel: the servant serves his master but by serving his master the servant little by little empties him, makes him devoid of any original initiative like an absent owner, reduces him to a pure façade and finally replaces him. Government grants money to science to achieve certain goals, to conduct a given set of research without knowing technical details and procedures and therefore without effective control. Thus, science de facto dedicates in the end to government what to do, and how, and how fast. No control is possible without actual knowledge. In the end, policy makers, despite all their rhetoric, are powerless when squarely faced by scientists.

The new emerging society, in this respect, cannot be labeled neither as a post-industrial society nor as a post-modern society nor purely and simply as a "knowledge society". ${ }^{7}$ Even less present day technically advanced societies can be defined in terms of "communicative action", as in Habermas, or as societies "produced" by debate, as in Touraine.

According to Robert E. Lane, there are five characteristics that define ${ }^{8}$ the knowledge society: 1) the basic beliefs about man, nature, and society itselfare constantly examined and called into question; 2) criteria for judgment are supposedly based on tested, therefore public and not merely private, truth; 3 ) considerable amount of resources is devoted to research; 4) collected data are continuously updated, interpreted and organized; 5) this cumulated knowledge is officially used to clarify values and goals of the global society. It seems that all these characteristics point to a common feature - knowledgeable societies have a great interest in knowledge. Whoever would judge that this is a vulgar truism, would certainly deserve lighter sentences because of attenuating circumstances? Perhaps, too many analysts are prone to state the obvious with an air of discovery. No doubt about the increased social significance of science in modern society. To think that the problem of interpretation of this society is solved by calling it "science", "knowledge", or "knowledgeable" society, begs the question.

\footnotetext{
${ }^{7}$ Cfr. R. E. Lane, "The Deeline of politics and Ideology in a Knowledgeable Society in American Sociological Review, n. 31. 1961, pp. 645-662. See also D. Bell, The Coming of Post-industrial Society, Basic Books, New York, 1989, Alvin W.Gouldner, The Future of Intellectuals and the Rise of Class, Seabury Press, New York, 1979.

${ }^{8}$ Cfr. J. Habernas, Theory of Communicative Action, Beacon Press, Boston, 1984; A. Touraine, Production de la société, Seuil, Paris, 1985.
} 
The object to be explained becomes the key to explanation. The great problem of technically advanced present day societies remains unsolved and looms large on all the marvelous scientific exploits at the threshold of the third millennium.

Knowledge, all types of knowledge including strict scientific knowledge, are not self-revealing. Like technology, knowledge cannot be regarded as a deus ex machine to be called upon to solve the society' problems that very often it has itself contributed decisively to create. Like technology, scientific knowledge is not only, as Heidegger would speculate, the eternal return of the identical. It has a mere instrumental value. Then, the basic question to ask is: knowledge for whom? For what?

We are thrown back to the underlying problem of power and its substantive legitimacy and its value- orientation. Science can clarify the issues, calculate the relative costs of the various alternative courses of action, show the best ways to implementation. However, it cannot take away from us the human, purely human responsibility of choice and decision. 